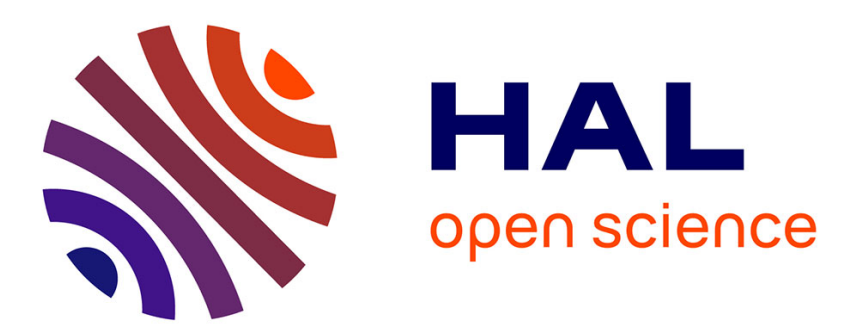

\title{
Characterisation and modelling of interfacial damage in fibre-reinforced concrete for 3D printing in construction
}

Nicolas Ducoulombier, Camille Chateau, Michel Bornert, Jean-François

Caron, Timm Weitkamp, Jonathan Perrin

\section{- To cite this version:}

Nicolas Ducoulombier, Camille Chateau, Michel Bornert, Jean-François Caron, Timm Weitkamp, et al.. Characterisation and modelling of interfacial damage in fibre-reinforced concrete for 3D printing in construction. 10th International Conference on Fracture Mechanics of Concrete and Concrete Structures, Jun 2019, Bayonne, France. 10.21012/FC10.235562 . hal-02263584

\section{HAL Id: hal-02263584 \\ https://hal-enpc.archives-ouvertes.fr/hal-02263584}

Submitted on 5 Aug 2019

HAL is a multi-disciplinary open access archive for the deposit and dissemination of scientific research documents, whether they are published or not. The documents may come from teaching and research institutions in France or abroad, or from public or private research centers.
L'archive ouverte pluridisciplinaire $\mathbf{H A L}$, est destinée au dépôt et à la diffusion de documents scientifiques de niveau recherche, publiés ou non, émanant des établissements d'enseignement et de recherche français ou étrangers, des laboratoires publics ou privés. 


\title{
CHARACTERISATION AND MODELLING OF INTERFACIAL DAMAGE IN FIBRE-REINFORCED CONCRETE FOR 3D PRINTING IN CONSTRUCTION
}

\author{
NICOLAS DUCOULOMBIER ", CAMILLE CHATEAU* ${ }^{*}$ MICHEL BORNERT ${ }^{*}$, JEAN- \\ FRANÇOIS CARON ${ }^{*}$, TIMM WEITKAMP ${ }^{\dagger}$ AND JONATHAN PERRIN ${ }^{\dagger}$
}

\author{
Laboratoire Navier, ENPC, IFSTTAR, CNRS, UMR 8205, Université Paris-Est, Marne-la-Vallée F-77455, \\ France \\ e-mail: nicolas.ducoulombier@enpc.fr, camille.chateau@enpc.fr, michel.bornert@enpc.fr, \\ jean-françois.caron@enpc.fr \\ ${ }^{\dagger}$ Synchrotron SOLEIL, St-Aubin 91192, France \\ e-mail: timm.weitkamp@ synchrotron-soleil.fr, jonathan.perrin@synchrotron-soleil.fr
}

Key words: Fiber-Reinforced Concrete, Interface, Damage, Tomography, 3D Printing, Micromechanical Testing

\begin{abstract}
Extrusion-based additive manufacturing of cementitious material is a promising technology for the future of construction. Nevertheless, new solutions need to be proposed to provide either ductility or even reinforcement in areas in tension. Using fibres to reinforce the structure made by extrusion seems to be promising and needs to be fully understood at different scales. Moreover, the efficiency of reinforcement depends mainly on the interfacial properties between matrix and fibres. Decohesion between matrix and fibre is studied at two different scales. A mesoscopic analytical mechanical model of a so-called tension stiffening test has been proposed to quantify resistance and friction along the interface from the force-elongation curve. Secondly, the same experimental test is performed inside the microtomography setup of the Anatomix beamline of Synchrotron Soleil permitting to identify the microscopic nature, shape and the evolution of decohesion between matrix and fibres for different loading. Different types of fibres are compared and different damaging mechanisms are observed.
\end{abstract}

\section{INTRODUCTION}

Additive fabrication of concrete is a promising technology for the future of construction, offering new architectural opportunities, increased flexibility and productivity. While additive manufacturing refers to various processes, we focus here on extrusion based additive fabrication. Because of the low resistance and brittle behaviour of traditional concrete in tension, new solutions need to be proposed to fully print complex structures, including areas in tension. Different strategies to reinforce the extruded concrete by adding short fibres or long cable are under development [1-3]. Thanks to the alignment of fibres during the extrusion process, this process seems to be efficient and promising. Indeed, one can make a full use of reinforcement in a given direction corresponding to the printing path. Short carbon fibres reinforced cement paste made by extrusion have been shown to exhibit very high tension strength [4]. Nevertheless, micromechanical explanations need to be provided to enhance the high potential of this family of material.

To better understand mechanical behaviour at different scale, this work focuses on the fibre/matrix interface as it strongly governs mechanical resistance and induces ductility of the reinforced material at macroscale. A socalled "tension-stiffening" micromechanical test has been developed to characterise the interfacial decohesion both at mesoscale using force-elongation curve and at microscale using microtomography 3D imaging. On one hand, a 
mesoscopic analytical mechanical model of this experiment has been proposed to quantify resistance and friction along the interface from the force-elongation curve. Then, this model is used to identify interfacial decohesion from comparison to experimental force-elongation curve obtained by digital image correlation (DIC) [5]. On the other hand, 3D images from $\mathrm{X}$-Ray microtomography are analysed using Digital Volume Correlation (DVC) and associated image subtraction techniques [9], to quantify the associated kinematic discontinuities, detect and characterise in 3D the microscopic nature and the evolution of the interfacial debonding.

\section{DETERMINATION OF INTERFACIAL MECHANICAL PROPERTIES USING MESOSCOPIC FORCE-ELONGATION CURVE}

Interfacial properties between matrix and fiber in composite material has broadly been studied. Numerous experimental tests have been proposed in literature to quantify strength and mechanical behavior depending on the material used and fiber geometry at different scale. Reviews of these investigations can be found in $[6,7]$.

Here, a so-called "tension-stiffening" (TS) micromechanical test has been developed to characterise the interface bonding, evolution of decohesion and friction. It consists in pulling on a single fibre locally embedded in the matrix on a ten to twenty mm long area (see Figure 1).

It was inspired by the traditional macroscale "tension stiffening" test used for the determination of rebar/concrete interfacial properties. It has been preferred over other existing micromechanical tests because of the simplicity of the boundary conditions and its capacity to identify mechanical properties of free fiber at the same time. General information about experimental and modelling part are specified hereafter.

\subsection{Fabrication of specimens and properties}

A specimen is made of a given fiber embedded on its central parts in a prismatic cementitious matrix.

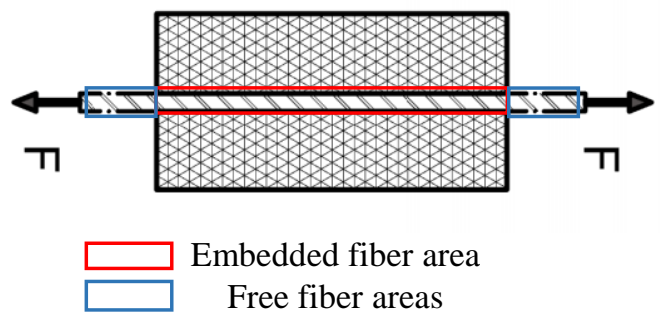

Figure 1: Schematic Tension Stiffening test

A special printable OPC mortar has been formulated (denominated Nav) and associated with two types of fibers. The first one is a single 100-micron diameter filament stainless steel fiber and the second one is a five hundred approx. 10 micron diameter filament basalt fiber. Fibers here can then refer either to single filament or multifilament fibers. Mechanical parameters are gathered in Table 1. The specimen is elaborated by casting the concrete in a 3D printed molds with one fiber passing through it. The mold is then cut or diluted to obtain the concrete specimen with a unique fiber at the center of the mortar section. Next, free basalt fiber areas (Figure 1) are impregnated with epoxy resin using a brush on area non-embedded in mortar. Later, the fiber is glued between two sheets of heavy paper. This permits to protect the specimen from unattended load when manipulated and to trap them in the clamping jaw during the test. Finally, a speckle pattern is applied on free fiber area using paint spray what provides the required image texture to apply DIC.

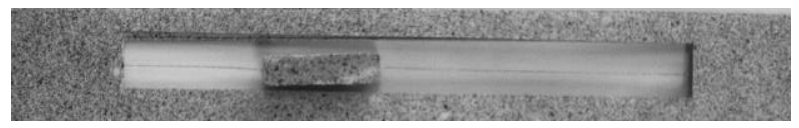

Figure 2: Protected and textured steel fiber TS specimen

\subsection{Experimental set-up}

The test is perform using a universal uniaxial machine. The force value is measured by a $100 \mathrm{~N}$ load cell and recorded by a national instruments (NI) card. The deformation of both embedded and free area of the fiber are measured by DIC. The set-up is composed of two cameras from Allied Vision equipped with 
optics from Schneider Kreuznach providing the appropriate optical magnification, close to unity, that record the same scene from two different viewpoints. The acquisition was led by MatLab thanks to an academic code based on the Image Acquisition and the Data Acquisition toolboxes of MatLab.

At any given time, it acquires and gathers one image per cameras and the force data from the NI cards. The optic of each camera was chosen to find a good compromise between getting enough pixels in the fiber diameter to be able to follow its movement during the test and showing a sufficient length in the longitudinal direction to measure the deformation of both embedded and free areas of the fiber. The experimental curves are given in Figure 4.

Table 1 : Material mechanical properties.

\begin{tabular}{cccc}
\hline Material & $\begin{array}{c}\text { Diameter } \\
(\mathbf{m m})\end{array}$ & $\begin{array}{c}\text { Young } \\
\text { Modulus } \\
(\mathbf{G P a})\end{array}$ & $\begin{array}{c}\text { Shear } \\
\text { Modulus } \\
(\mathbf{G P a})\end{array}$ \\
\hline Nav & 3 & 40 & 16,3 \\
\hline $\begin{array}{c}\text { Stainless } \\
\text { steel }\end{array}$ & 0.1 & 175 & 67,3 \\
\hline basalt* & $0.2^{*}$ & $100^{*}$ & $38.5^{*}$ \\
\hline
\end{tabular}

* For multifilament fibers, diameters and mechanical properties are indicative. They are calculated fixing the diameter to $\mathrm{d}=0.2 \mathrm{~mm}$ and Poisson Ratio to $v=0.25$ and calculating the young modulus $\mathrm{E}=4 * \mathrm{~K} / \pi \mathrm{d}^{2}$ and the shear modulus $G=E / 2(1+v)$ with $K$ being the free fiber stiffness experimentally measured by the setup.

\subsection{Data processing}

In order to get the experimental forceelongation curves, deformation from both free and embedded fiber parts are obtained using multiple DIC. This technique is used to remove from the apparent deformation of one camera, the contribution due to the out-of-plane rigid motion detected by the other camera. Only final curves are presented here for brevity.

\subsection{Modelling}

A mesoscopic analytical model of this test has been proposed to quantify resistance and friction along the interface from the force- elongation curve. It is derived by associating a reduced multi-particle 1D model and a particular mechanical behaviour at the interface. The reduction from 3D model to $1 \mathrm{D}$ model is performed using Hellinger-Reissner formulation. This technique was first developed and was successfully used from $3 \mathrm{D}$ to $2 \mathrm{D}$ to efficiently model a multi-layer material in [8]. Here, only main notations, hypothesis and the final set of equations are provided:

- Notations:

$F_{m}$ : Matrix internal force

$F_{f}$ : Fiber internal force

$\tau_{\text {ext }}:$ Matrix external shear stress

$\tau_{i}:$ Interfacial shear stress

$Q_{\text {ext }}$ : Generalized matrix external shear stress

$Q_{i}$ : Generalized interfacial shear stress

$U_{f}$ : Generalized 1D fiber displacement

$U_{m}$ : Generalized 1D matrix displacement

$\varepsilon_{f}:$ Generalized 1D fiber displacement

$\varepsilon_{m}$ : Generalized 1D matrix displacement

$E_{f}$ : Fiber young modulus

$E_{m}$ : Matrix young modulus

$G_{f}$ : Fiber shear modulus

$G_{m}$ : Matrix shear modulus

- Hypothesis:

1) Fibres and matrix are isotropic and elastic

2) Only one dimensional interfacial inelastic effect is kept.

3) Supposed to be a plastic-softening

- Equilibrium:

$\frac{d F_{m}(z)}{d z}+Q_{e x t}(z)-Q_{i}(z)=0$

$\frac{d F_{f}(z)}{d z}+Q_{i}(z)=0$

with $Q_{i}(z)=\tau_{i}(\mathrm{z}) * 2 \pi \mathrm{R}_{\mathrm{f}}$ and $\operatorname{Qext}(z)=\tau_{e x t}(\mathrm{z}) * 2 \pi \mathrm{R}_{\mathrm{m}}$

- Boundary conditions:

$\mathrm{Q}_{\mathrm{ext}}=$ given

$\mathrm{CL} 1:=\mathrm{F}_{\mathrm{f}}(\mathrm{l})=$ given

CL2 $:=F_{f}(0)=$ given

- Elastic behavior: 


$$
\begin{aligned}
& \varepsilon_{\mathrm{f}}(\mathrm{z})=\frac{d U_{f}(z)}{d z}=\frac{\mathrm{F}_{\mathrm{f}}(\mathrm{z})}{\pi * \mathrm{R}_{\mathrm{f}}{ }^{2} * \mathrm{E}_{\mathrm{f}}} \\
& \varepsilon_{\mathrm{m}}(\mathrm{z})=\frac{d U_{m}(z)}{d z}=\frac{\mathrm{F}_{\mathrm{m}}(\mathrm{z})}{\pi *\left(\mathrm{R}_{\mathrm{m}}{ }^{2}-\mathrm{R}_{\mathrm{f}}{ }^{2}\right) * \mathrm{E}_{\mathrm{m}}} \\
& \Delta U(z)=U_{m}(z)-U_{f}(z)=\frac{Q_{i}(z)}{8} * \\
& \left(\frac{1}{\pi G_{f}}+\frac{\left(4 * \ln \left(\frac{\mathrm{R}_{\mathrm{m}}}{R_{f}}\right) * \mathrm{R}_{\mathrm{m}}{ }^{4}-\mathrm{R}_{\mathrm{f}}{ }^{4}+4 \mathrm{R}_{\mathrm{m}}{ }^{2} * \mathrm{R}_{\mathrm{f}}{ }^{2}-3 \mathrm{R}_{\mathrm{m}}{ }^{4}\right)}{G_{m} * p i *\left(\mathrm{R}_{\mathrm{m}}{ }^{2}-\mathrm{R}_{\mathrm{f}}{ }^{2}\right)^{2}}\right)
\end{aligned}
$$

- Interfacial decohesion:

Strength domain writes:

$$
\left\{\begin{array}{c}
f\left(Q_{i}\right)=\left|Q_{i}\right|-\left(Q_{\max }-K_{d} \times\left|u_{i}\right|\right) \text { if } Q_{\max }-K_{d} \times\left|u_{i}\right|<Q_{f} \\
f\left(Q_{i}\right)=\left|Q_{i}\right|-Q_{f} \text { if } Q_{\max }-K_{d} \times\left|u_{i}\right| \geq Q_{f}
\end{array}\right.
$$

Radial return writes:

$$
\dot{u}_{\mathrm{i}}=\dot{\lambda} \times \frac{\partial f}{\partial Q_{i}}
$$

Inelastic interfacial behavior:

$$
Q_{i}(x)=K_{i} \times\left(U_{m}(x)-U_{f}(x)-u_{i}(x)\right)
$$

Here, interfacial decohesion is seen as a plastic softening behavior. But this could also be transposed to a damage behavior using one parameter affecting the interfacial stiffness. The best choice between those two visions is difficult without more information on the decohesion nature at smaller scale.

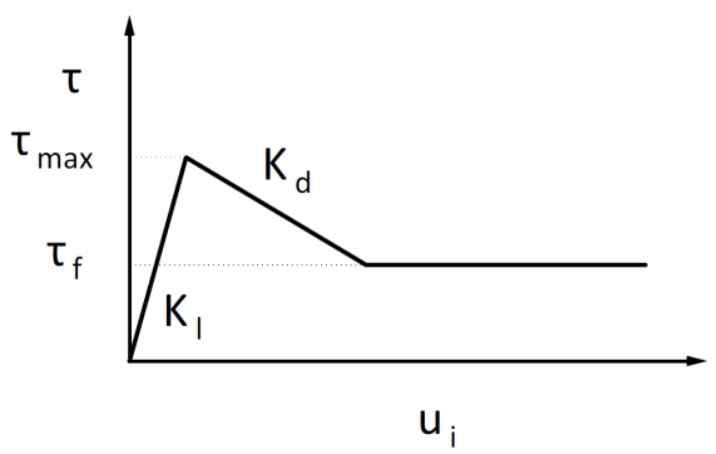

Figure 3: Trilinear Interfacial Behavior.

\subsection{Identification of interfacial properties}

From now, we keep our plastic modelling of interfacial decohesion and choose a trilinear curve for elastic, softening and frictional behavior of the interface represented in Figure 3.
Table 2: Identified interface mechanical properties.

\begin{tabular}{ccccc}
\hline Interface & $\begin{array}{c}\boldsymbol{K}_{\boldsymbol{i}} \\
(\mathbf{G P a} / \\
\mathbf{m m})\end{array}$ & $\begin{array}{c}\boldsymbol{K}_{\boldsymbol{d}} \\
(\mathbf{G P a} / \\
\mathbf{m m})\end{array}$ & $\begin{array}{c}\boldsymbol{\tau}_{\max } \\
(\mathbf{M P a}\end{array}$ & $\begin{array}{c}\boldsymbol{\tau}_{f} \\
(\mathbf{M P a}\end{array}$ \\
\hline Basalt & 40 & 0 & 33 & $?$ \\
\hline $\begin{array}{c}\text { Stainless } \\
\text { steel }\end{array}$ & inf & 0.24 & 9 & 0.2 \\
\hline
\end{tabular}

Figure 4 presents comparison between experimental and simulated force-elongation curves for the two different specimens. Identified interfacial properties are then gathered in table 4.

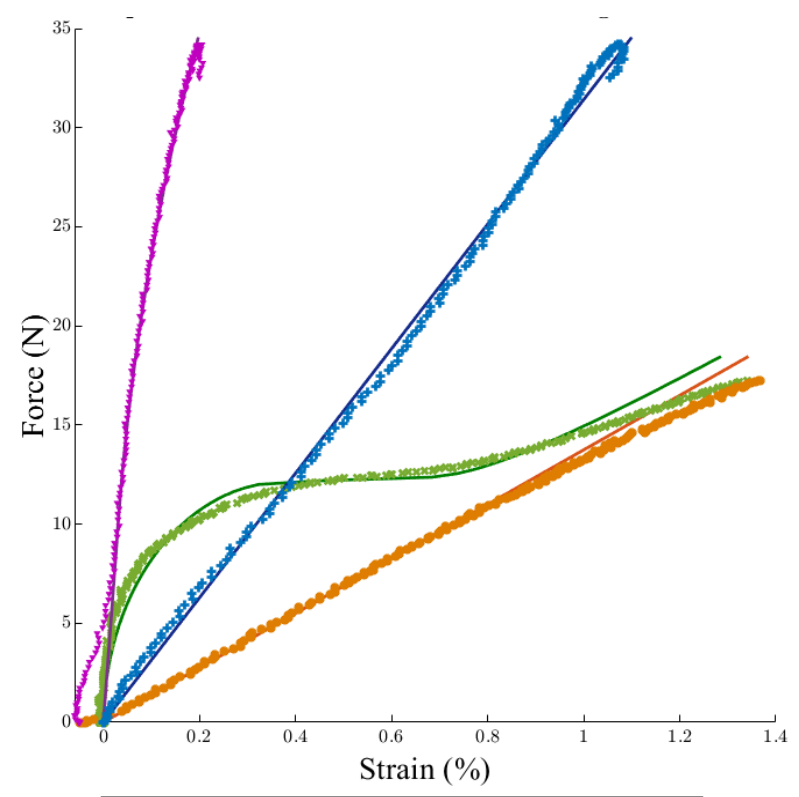

\begin{tabular}{|l|}
\hline - Simulated stainless steel composite \\
- Simulated stainless steel fiber \\
$*$ Experimental stainless steel composite \\
- Experimental stainless steel fiber \\
Simulated basalt composite \\
\hline Simulated basalt fiber \\
- Experimental basalt composite \\
\hline
\end{tabular}

Figure 4 : Comparison between experimental and simulated Force-Elongation curves

This analysis shows a good agreement between experimental and simulated curves. The stainless curves are interesting because their late superposition shows that interface is completely debonded at the end of the test. Compared to these reference curves, the basalt ones highlight the fact that interfacial properties of multifilament basalt fiber is much higher than single filament stainless steel fiber. The beginning of the basalt composite force- 
elongation curves seems to be due to fiber curvature and stress repartition at the beginning of the test.

\section{IDENTIFICATION OF DAMAGE NATURE BY MICROTOMOGRAPHY AND IN SITU TESTING}

In order to confirm (or to enhance) the assumption and to explain results of the mesoscopic model, microtomography imaging is used to fully characterize the damage mechanisms at microscopic scale involved in the load distribution between mortar and fibers. The aim is to detect and characterize in 3D the microscopic nature and the evolution of interfacial debonding and associated damage mechanisms in the matrix close to the reinforcement. The $3 \mathrm{D}$ images were acquired at synchrotron Soleil on the recently developed beamline Anatomix [10], with a voxel size of $0.65 \mu \mathrm{m}$ and an image definition of $2048^{3}$ voxels per acquisition, so that one acquisition covers an area of $1.3^{3} \mathrm{~mm}^{3}$. As the diameter of the mortar prism is approximately three millimeters. Only surrounding mortar around the fiber is included in the 3D images. In order to get a volume including all the interface along the sample, successive acquisitions at subsequent heights were performed along the embedded fiber area. One acquisition lasts approximately $3 \mathrm{~min}$.

\subsection{Experimental Set-up}

A specific set-up has been designed and made to be able to realize the same experiments on the same kind of specimen inside the microtomograph. Details are shown on Figure 5.

A reference acquisition was performed with a very small loading but sufficient to straighten the specimen. Then, loading was applied by hand using the micrometric screw until the aimed force value, monitored by the load sensor, was reached. The operation was

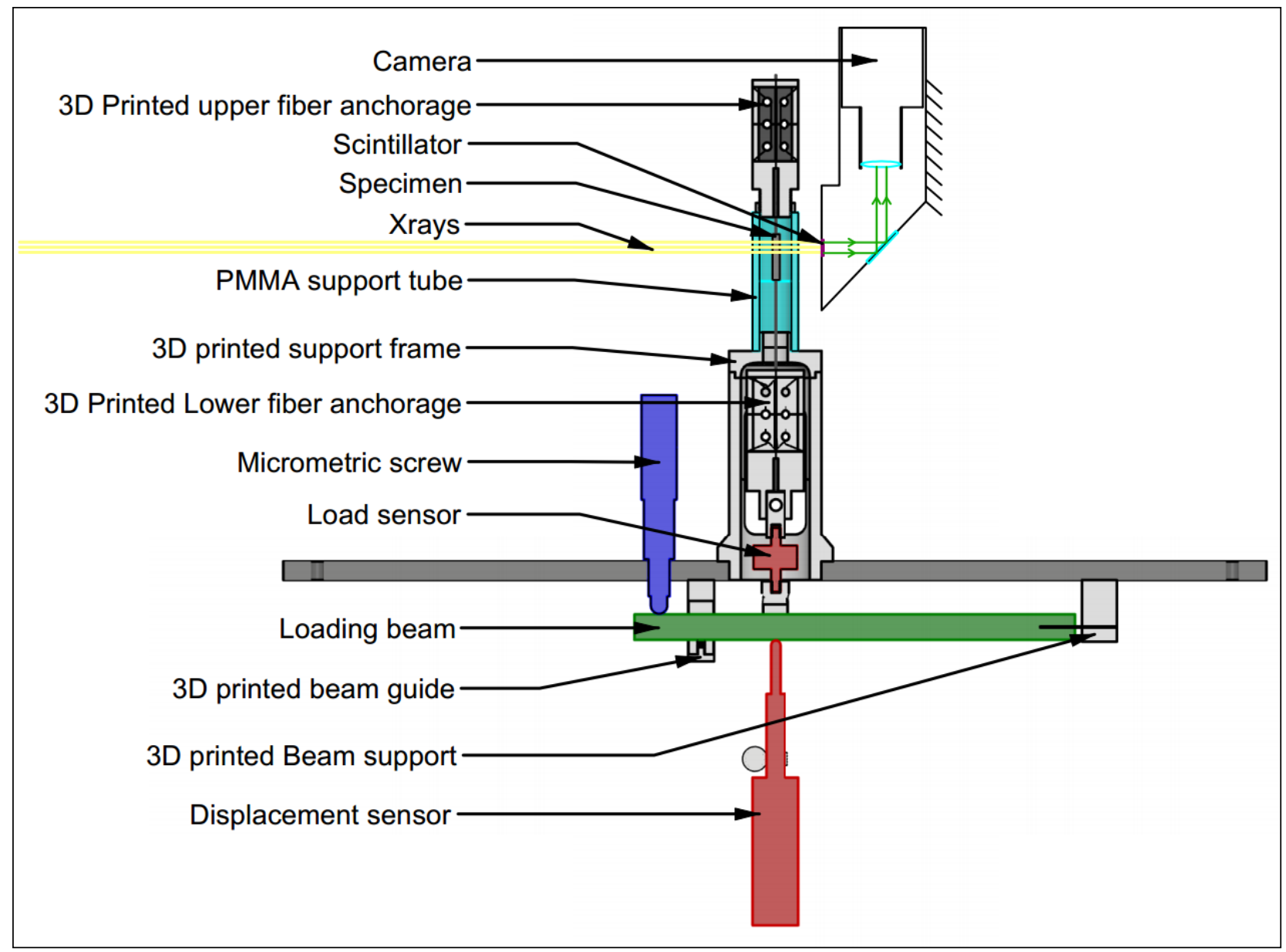

Figure 5: In situ experimental tension stiffening set up 
executed typically five times. The aim was to capture the initiation of the debonding and its evolution for different load values.

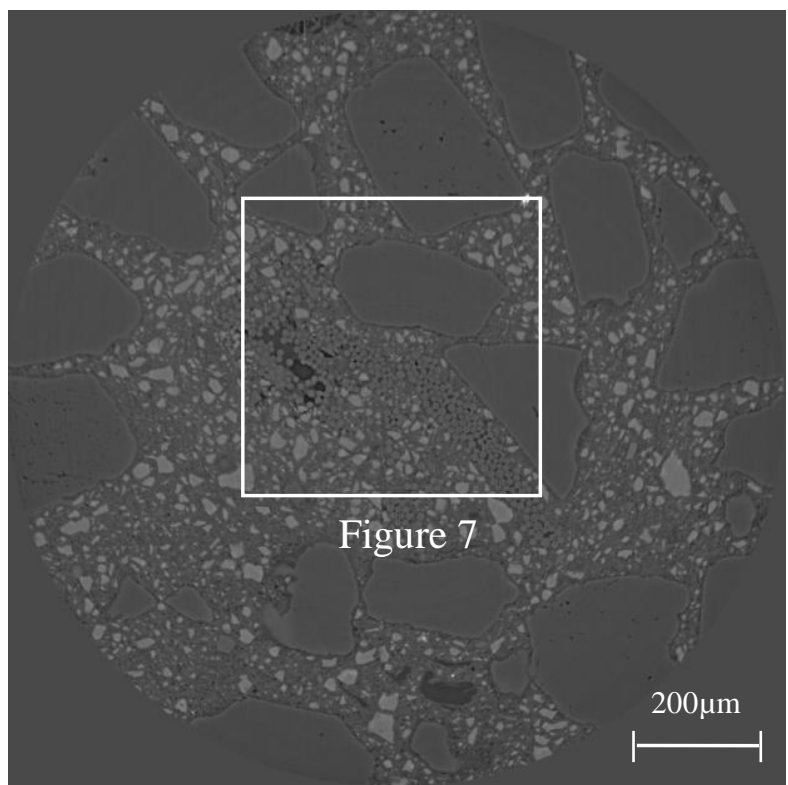

Figure 6: Cross section of reference volume of basalt fiber embedded in mortar

\subsection{Images processing}

For each subvolume, three main action should be performed. The first one is to reduce 32 bits volumes to 8 bits volume that are easier to process thanks to smaller memory allocation. In this step, grey level bounds needs to be chosen carefully to insure that no information on microstructure are lost.

The second one consists in applying DVC algorithms to map the reference volume and a volume under load at a certain level. DVC is performed using CMV3D, an academic software developed by Bornert and al $[9$ ou Bornert et al 2004]. A regular grid of points is first generated. And, in order to guaranty a good accuracy of measurement, only points with sufficient local mean value and variance of grey levels are kept for deformation mapping by DVC, respectively superior to 50 and 0.05 and calculated on $30^{3}$ voxels subvolumes for each point of the initial grid. As a consequence, final points that will be used for DVC are mostly located in the cement paste. The correlation window is set to $30^{3}$ voxels and the critical correlation coefficient (Zero-mean Normalized Cross Correlation) value is set to 0.15 .
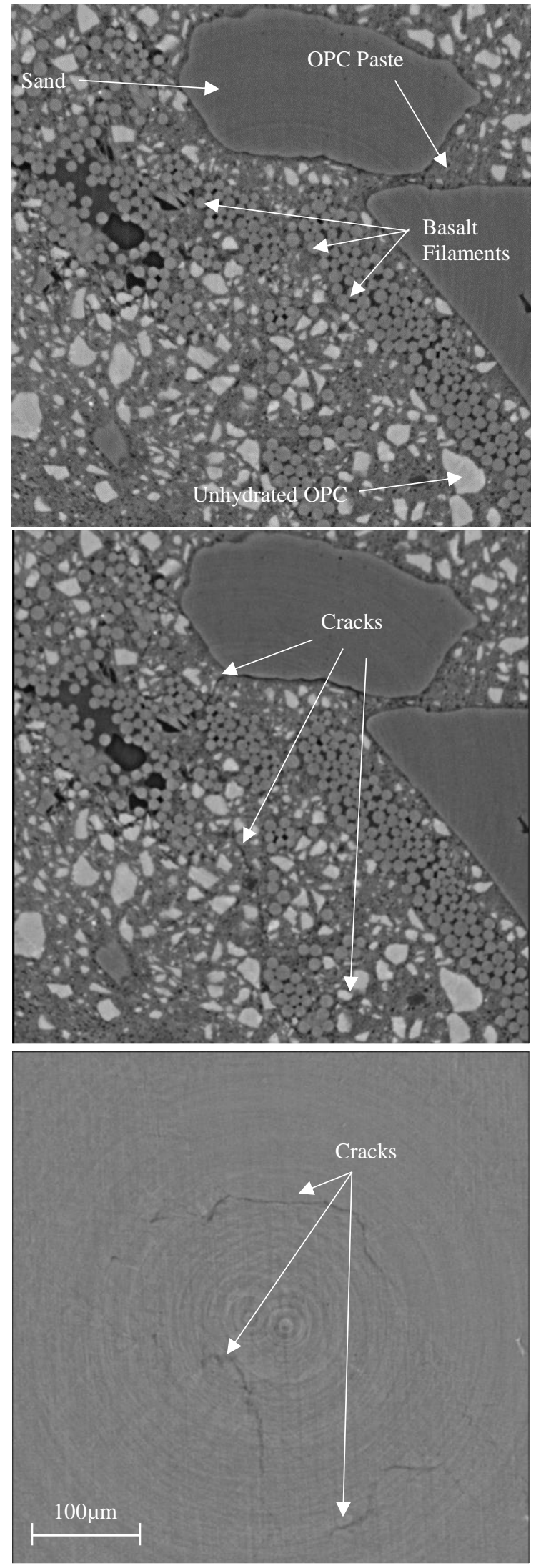

Figure 7: Zoomed cross section of basalt reference subvolume (top), rebuilt damaged subvolume at $35 \mathrm{~N}$ (top), substracted subvolume (bottom) 
Finally, appropriate image substraction is performed. The principle is to rebuild the damaged volume in the reference position. More precisely, the correspondent grey level in damaged volume can be attributed for each pixel in the reference position using local transformation fitted over a set of nearest correlated points, the size of which defines the local smoothing of the mapping. Then, the subtraction between the rebuilt damage volume and the reference volume can be performed. The resulted volume should suppress all the microstructure information and only contain the difference between both images associated with high frequency kinematic phenomena not described in the smoothed mapping, including essentially cracks as shown in Figure 7 and Figure 8. More information about the substraction technique can be found in [9].

\subsection{Damage nature}

As in situ experimental tests were performed very recently, the full processing of all data is still underway. In the present paper, we thus focus on the very first remarkable result, which shows that two remarkable and very different decohesion mechanisms are observed, depending on the considered fiber. These events are obtained when processing two subvolumes obtained at the reference and the last force value before ruin, centered on the fibers axis and located at approximately $2 \mathrm{~mm}$ inside the mortar. Two main kinds of damage pattern can be observed, respectively in Figure 7-Figure 9 and Figure 8-Figure 10:

The first damage pattern shows cohesive cracks in the surrounding matrix. Cracks are conical and emitted from the interface. The cracks propagation seems to be limited in a small matrix cylinder centered on the fiber, the precise extension still needs to be quantified. Moreover, the cones are more or less flattened depending on the fiber shape. This kind of damage is very efficient as it produces multi cohesive cracking of the matrix that allows for a great energy dissipation.
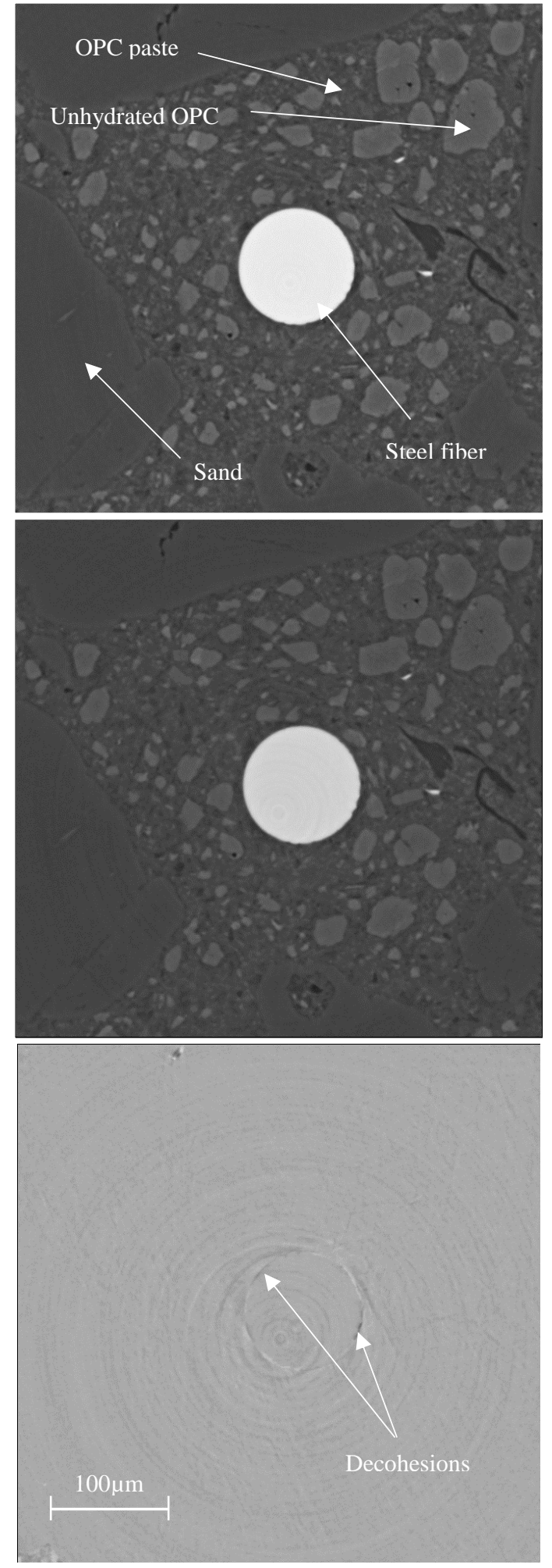

Figure 8: Zoomed cross-section of stainless steel reference subvolume (top), rebuilt damaged subvolume at $15 \mathrm{~N}$ (top), substracted subvolume (bottom)

This observation confirms the result obtained from the study of the force-elongation curve and calls for a damage or fracture mechanics analysis rather than plasticity. 
The second damage pattern does not show any crack in the matrix. But one can guess a tiny decohesion area located along the fiber from Figure 8 and Figure 10. Here, debonding is located at the immediate vicinity of the fiber with no propagation to the surrounding matrix. This observation confirms that the anchorage of steel fiber should be much lower than basalt fiber. Moreover, elastoplastic modelling of the interface seems this time more fitted.

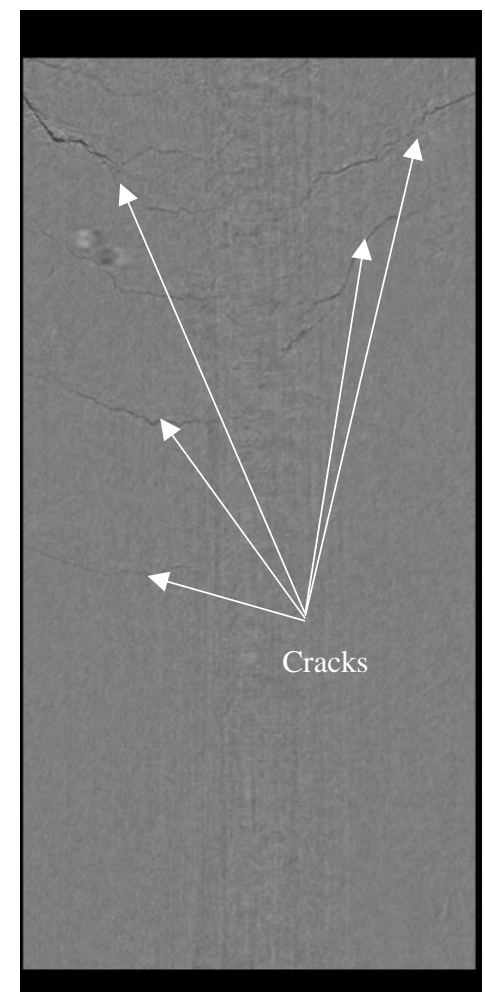

Figure 9: Longitudinal section of basalt subvolume obtained by image substraction.

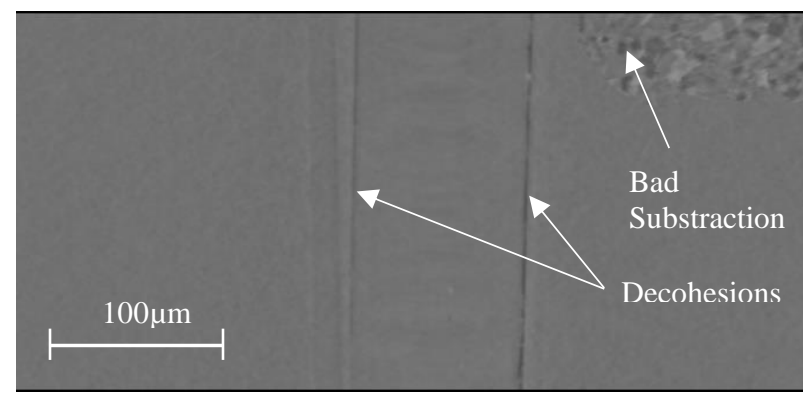

Figure 10: Longitudinal section of stainless steel subvolume obtained by image substraction.

\section{CONCLUSION}

The present paper aims to study interfacial decohesion of different fibers in a printable OPC mortar at two different scale from the same tension stiffening experiment. From the mesoscopic point of view, a reduced model is proposed and associated with an elastoplastic interfacial law, allows for simulating theoretical force-elongation curve. By comparison with experimental results, interface mechanical parameters can be identified. Key results are listed here:

- Good agreement is found between simulated and experimental ForceElongation curve

- Multifilament basalt fiber interfacial properties are remarkable and much higher than single filament stainless steel fiber.

- The interfacial stress up to $33 \mathrm{MPa}$ does not have a clear physical meaning and requires for more investigation.

The same experimental test is run inside microtomography setup of the Anatomix synchrotron beamline. First observations of damage nature give important complementary results:

- Multifilament basalt fiber shows cohesive multi cracking of the surrounding matrix.

- Single filament steel fiber shows a much more located interfacial decohesion.

By gathering analysis at two different scales, the paper shows that depending on the fiber, different decohesion mode can occur at interface, what will affect the force elongation curve.

- Very localized decohesion around the steel fiber confirms the proposed modelling and lead to interfacial properties that are controlled by the immediate vicinity of the fiber surface.

- Interfacial decohesion in multifilament basalt fiber, involves cohesive multicracking of the surrounding matrix.

This increases drastically the interface properties and calls for a modification in the modelling assumptions that was made in the present work, using 
damage or fracture mechanics

hypothesis rather than elastoplasitcity.

\section{REFERENCES}

[1] D. G. Soltan and V. C. Li, 2018. A selfreinforced cementitious composite for building-scale 3D printing, Cement and Concrete Composites, 90:1-13.

[2] Bos, F., Ahmed, Z., Jutinov, E., Salet, T., 2017. Experimental Exploration of Metal Cable as Reinforcement in 3D Printed Concrete. Materials, 10:1314.

[3] Bos, F., Bosco, E., Salet, T.A.M., 2019. Ductility of 3D printed concrete reinforced with short straight steel fibers. Virt. and Phys. Prot., 14:160-174.

[4] Hambach, M., Möller, H., Neumann, T., Volkmer, D., 2016. Portland cement paste with aligned carbon fibers exhibiting exceptionally high flexural strength $(>100$ MPa). Cem. and Conc. Res. 89:80-86.

[5] N. Ducoulombier, C. Chateau, J.-F. Caron, M. Bornert, H. Bessaies-Bey and N. Roussel, 2018. Micromechanical testing for a 3D-printed long fiber reinforced concrete. Poster, Dig. Conc. 2018

[6] Teklal, F., Djebbar, A., Allaoui, S., Hivet, G., Joliff, Y., Kacimi, B., 2018. A review of analytical models to describe pull-out behavior - Fiber/matrix adhesion. Comp. Struct. 201:791-815.

[7] Zhandarov, S., 2005. Characterization of fiber/matrix interface strength: applicability of different tests, approaches and parameters. Comp. Sci. and Tech. 65:149-160

[8] Thai, N.D., D’Ottavio, M., Caron, J.-F., 2013. Bending analysis of laminated and sandwich plates using a layer-wise stress model. Comp. Struct. 96:135-142.

[9] C. Chateau, T. T. Nguyen, M. Bornert, and
J. Yvonnet, 2018. DVC-based image subtraction to detect microcracking in lightweight concrete, Strain, vol. 54(5): 12276

[10] T. Weitkamp, M. Scheel, J.L. Giorgetta, V. Joyet, V. Le Roux, G. Cauchon, T.Moreno, F. Polack, A. Thompson, J.P. Samama, 2017. The tomography beamline ANATOMIX at Synchrotron SOLEIL Jour. of Phys.: Conf. Ser. 849 (1):012037, 